\title{
Thiophosphation of 2-Methyl-2-Nitro-1-Propanol and the Preparation of Monothiophosphoric Acid
}

\author{
J. V. Karabinos, R. A. Paulson, and W. H. Smith
}

\begin{abstract}
The thiophosphation of a nitroalcohol was studied in ether and in pyridine solution. When 2-methyl-2-nitro-1-propanol was refluxed with phosphorus pentasulfide in ether, the corresponding dithiophosphate was formed. In pyridine solution, however, a pyridine salt of the secondary dithiophosphate was formed. A pyridine salt of metatrithophosphoric acid was also isolated from the latter reaction, and this salt was hydrolyzed to pyridinium monothiophosphate. Monothiophosphoric acid monohydrate itself was obtained, for the first time, by application of ion-exchange and lyophilizing techniques to its pyridine salt.
\end{abstract}

\section{Introduction}

The reaction of phosphorus pentasulfide with organic hydroxy compounds reportedly $\left[\begin{array}{lll}1 & \text { to } & 4\end{array}\right]^{1}$ yields secondary dithiophosphates (I).

$$
(\mathrm{RO})_{2} \mathrm{P}(\mathrm{S}) \mathrm{SH} \text {. }
$$

An extension of this reaction to a nitroalcohol is described. When 2-methyl-2-nitro-1-propanol was refluxed with phosphorus pentasulfide in ethyl ether, a product melting at $104^{\circ} \mathrm{C}$ was obtained that gave elemental analyses and a molecular-weight value corresponding to $\mathrm{O}, \mathrm{O}^{\prime}$-bis $(2$-methyl-2-nitro-propyl-) dithiophosphate (II).

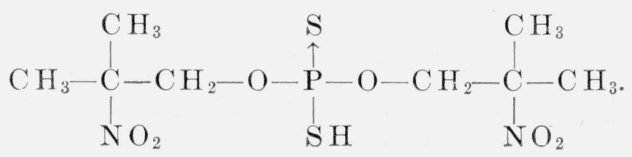

Phosphorus pentasulfide in pyridine solution has been recently reported [5] to give thiation of certain pyridones. In a study of the action of phosphorus pentasulfide on 2-methyl-2-nitro-1-propanol in pyridine solution at the Bureau, a yellow, extremely hygroscopic substance crystallized directly from the pyridine solution; this substance gave elemental analyses corresponding to $\mathrm{C}_{10} \mathrm{H}_{11} \mathrm{~N}_{2} \mathrm{PS}_{3}$ (III). Upon standing exposed to the atmosphere, substance III took up moisture with considerable foaming and evolution of hydrogen sulfide and, in a relatively short time, a colorless solution was obtained, from which white cube-like crystals appeared. After purification, the latter substance (IV) gave analyses corresponding to $\mathrm{C}_{5} \mathrm{H}_{8} \mathrm{O}_{3} \mathrm{NSP}$. Substance IV liberated pyridine under alkaline conditions, and hydrogen sulfide with dilute acids. A positive sulfhydryl test was given by III, although not by IV. Substances III and IV are probably pyridinium salts, the former a salt of pyridine with metatrithiosphoric acid, $\mathrm{HPS}_{3}$, a thioanalog of metaphosphoric acid, and the latter a pyridine salt of monothiophosphoric acid, $\mathrm{H}_{3} \mathrm{PSO}_{3}$. This latter acid, a monothio analog of phosphoric acid, could arise from $\mathrm{HPS}_{3}$ by hydrolysis, with the liberation of hydrogen sulfide.

\footnotetext{
1 Figures in brackets indicate the literature references at the end of this paper.
}

$$
\mathrm{HPS}_{3}+3 \mathrm{H}_{2} \mathrm{O} \rightarrow \mathrm{H}_{3} \mathrm{PSO}_{3}+2 \mathrm{H}_{2} \mathrm{~S} .
$$

The formuias for the pyridinium salts III and IV may be represented as follows:

$$
\left(\mathrm{C}_{5} \mathrm{H}_{5} \mathrm{~N}\right)_{2} \cdot \mathrm{HPS}_{3} . \quad \text { (III). } \quad \mathrm{C}_{5} \mathrm{H}_{5} \mathrm{~N} \cdot \mathrm{H}_{3} \mathrm{PSO}_{3} .
$$

It is possible that substance III, rather than phosphorus pentasulfide, acts as the thiating agent in pyridine solution [5].

From the mother liquors obtained by the reaction of phosphorus pentasulfide with the nitroalcohol in pyridine solution, still another crystalline substance was obtained; this substance melted at $103^{\circ}$ to $104^{\circ} \mathrm{C}$ and gave analyses corresponding to the formula $\mathrm{C}_{13} \mathrm{H}_{22} \mathrm{O}_{6} \mathrm{~N}_{3} \mathrm{~S}_{2} \mathrm{P}(\mathrm{V})$. As pyridine was obtained upon the addition of alkali to $V$ and hydrogen sulfide was liberated in acidic solution, $V$ was suspected of being a pyridinium salt of $\mathrm{O}, \mathrm{O}^{\prime}$-bis $(2$-methyl-2-nitropropyl-)dithiophosphoric acid.

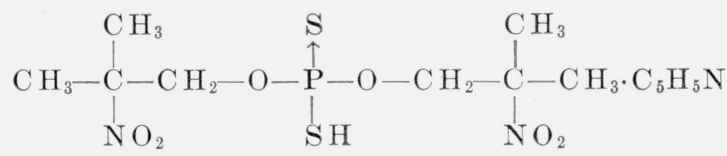

This was confirmed by the isolation of the secondary dithiophosphate (II) from the eluate upon removal of pyridine with a cation exchange resin.

The over-all equations for the action of phosphorus pentasulfide on 2-methyl-2-nitro-1-propanol in pyridine solution may be expressed as follows:

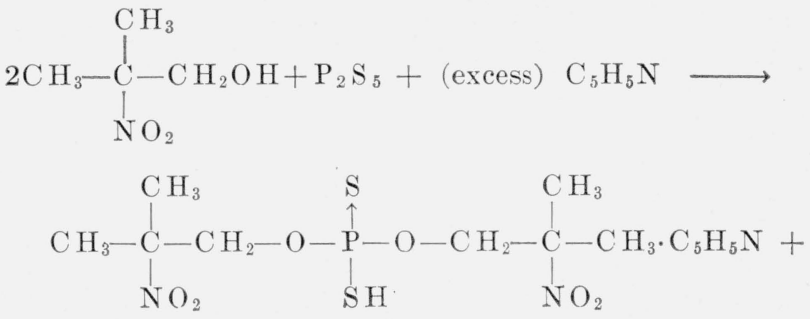

$\left(\mathrm{C}_{5} \mathrm{H}_{5} \mathrm{~N}\right)_{2} \cdot \mathrm{H} \mathrm{P} \mathrm{S}_{3}$.

In a similar manner monothiophosphoric acid, $\mathrm{H}_{3} \mathrm{PSO}_{3}$, was isolated from its pyridinium salt (IV) by removal of the pyridine with the cation exchange resin, Amberlite IR-100-H, followed by lyophilization 
("freeze-drying") of the eluate. The sirupy product gave sulfur and phosphorus analyses and a neutralization equivalent corresponding to a monohydrate, which was relatively stable at $-20^{\circ} \mathrm{C}$, although it decomposed slowly at room temperature, as reported in the early literature [6].

\section{Experimental Details}

\subsection{Reaction of 2-Methyl-2-Nitro-1-Propanol with Phosphorus Pentasulfide in Ethyl Ether}

O,O'-Bis (2-methyl-2-nitro-propyl-) Dithiophosphate

To $30 \mathrm{~g}$ of 2-methyl-2-nitro-1-propanol dissolved in $150 \mathrm{ml}$ of ethyl ether was added $30 \mathrm{~g}$ of phosphorus pentasulfide, and the mixture was maintained at reflux for $16 \mathrm{hrs}$. The white, fluffy needles that had formed in good yield were collected by filtration and dried in a vacuum desiccator. After several recrystallizations from ether, a product with a constant melting point of $103.8^{\circ}$ to $104^{\circ} \mathrm{C}$ was obtained. The substance, unlike the original nitroalcohol, was insoluble in water, and purification could also be effected by aqueous extraction.

Analysis: Calculated for $\mathrm{C}_{8} \mathrm{H}_{17} \mathrm{O}_{6} \mathrm{~N}_{2} \mathrm{~S}_{2} \mathrm{P}$ : C, 28.91; H, 5.16; S, 19.29; P, 9.32; Molecular Weight, 332. Found: C, 29.01 ; H, 5.10 ; S, 19.70 ; P, 9.26 ; molecular Weight (Rast), 322.

\subsection{Reaction of 2-Methyl-2-Nitro-1-Propanol with Phosphorus Pentasulfide in Pyridine}

\section{a. Pyridine Salt of Metatrithiophosphoric Acid}

Phosphorus pentasulfide $(25 \mathrm{~g})$ was dissolved in $150 \mathrm{ml}$ of pyridine containing $12 \mathrm{~g}$ of 2-methyl-2nitro-1-propanol, and the mixture was refluxed for $1 \frac{1}{2}$ hrs. Upon cooling the solution, yellow prisms began crystallizing; the process was allowed to continue overnight. The crystalline product was collected by filtration, washed with ethyl ether, and dried in a vacuum desiccator for several days. The weight of product $(29 \mathrm{~g})$ corresponded to a theoretical yield of 90 percent. The substance was stable in a desiccator but decomposed rapidly when exposed to atmospheric moisture. It gave a positive sulfhydryl test with nitroprusside reagent and melted in the neighborhood of $90^{\circ}$ to $100^{\circ} \mathrm{C}$, although the melting point was not at all well defined because of foaming and the hygroscopic character of the substance.

Analysis: Calculated for $\mathrm{C}_{10} \mathrm{H}_{11} \mathrm{~N}_{2} \mathrm{PS}_{3}$ : C, 41.94; H, 3.87; P, 10.82; S, 33.59. Found: C, 41.95; H, $3.71 ; \mathrm{P}, 10.80 ; \mathrm{S}, 33.70$.

\section{b. Pyridine Salt of O, O'-Bis (2-Methyl-2-Nitro-Propyl-) Dithiophosphate (V)}

The mother liquor from which the pyridine salt of Metatrithiophosphoric acid (III) was obtained was poured into $500 \mathrm{ml}$ of water, and a small amount of precipitated sulfur was removed by filtration. The clear solution was then concentrated to a crystalline residue in a current of dry air, and the crystals were extracted with a small amount of water, collected by filtration, and dried. The crude pyridine salt of O,O'-bis (2-methyl-2-nitro-propyl-) dithiophosphate (V) weighing $15 \mathrm{~g}$ was purified for analyses by recrystallization from dioxane-ether $(1: 1)$ and finally from ethanol-ether $(1: 1) ; \mathrm{mp}, 103^{\circ}$ to $104^{\circ} \mathrm{C}$.

Analysis: Calculated for $\mathrm{C}_{13} \mathrm{H}_{22} \mathrm{O}_{6} \mathrm{~N}_{3} \mathrm{~S}_{2} \mathrm{P}: \mathrm{C}, 37.95$; H, 5.39; S, 15.58; P, 7.53. Found: C, 38.25; H, $5.40 ; \mathrm{S}, 15.98 ; \mathrm{P}, 7.55$.

\section{c. Isolation of $\mathrm{O}, \mathrm{O}^{\prime}$-Bis (2-Methyl-2-Nitro-Propyl-) Dithiophosphate (II) From Its Pyridine Salt (V)}

Five milliliters of an aqueous solution containing $0.5 \mathrm{~g}$ of the pyridine salt (V) was passed through a column (1.0 by $10 \mathrm{~cm})$ of Amberlite IR-100-H, analytical grade, and a sufficient volume of distilled water was then passed through the column to elute the dithiophosphate. The eluate was concentrated in a current of dry air to a high yield of crystalline residue, which was purified by recrystallization from ethyl ether. The product melted sharply at $104^{\circ} \mathrm{C}$ and showed no melting-point depression upon admixture with the $\mathrm{O}, \mathrm{O}^{\prime}$-bis $(2-$ methvl-2-nitro-propyl-)dithiophosphate prepared in ether solution.

\section{d. Hydrolysis of Pyridinium Metatrithiophosphate (III) Pyridine Salt of Monothiophosphoric Acid (IV)}

Although hydrolysis of III could be effected by atmospheric moisture, $4.2 \mathrm{~g}$ of pyridinium metatrithiophosphate was dissolved in $3 \mathrm{ml}$ of water. Vigorous evolution of gas occurred, and the odor of hydrogen sulfide was pronounced. After the solution had stood for $1 \mathrm{hr}$, the excess moisture was removed in a current of dry air, and the resultant sirup began to crystallize. Crystallization was hastened by addition of small amounts of ethanol. The cube-like crystals were collected by filtration and dried in vacuo. The product weighed $2 \mathrm{~g}$, corresponding to 71 percent of the theoretical vield. The product was recrystallized from 95-percent ethanol for analysis. It did not give a sulfhydryl test, although it liberated pyridine on treatment with dilute alkali and hydrogen sulfide upon the addition of dilute acids. The purified pyridinium monothiophosphate melted at $116^{\circ} \mathrm{C}$, with evolution of gas.

Analysis: Calculated for $\mathrm{C}_{5} \mathrm{H}_{8} \mathrm{O}_{3} \mathrm{NPS}$ : C, 31.92; $\mathrm{H}, 4.17 ; \mathrm{P}, 16.04 ; \mathrm{S}, 16.60$. Found: C, 31.95; H, $4.43 ; \mathrm{P}, 15.92 ; \mathrm{S}, 16.89$.

\subsection{Preparation of Monothiophosphoric Acid Monohydrate}

A solution containing $1 \mathrm{~g}$ of pyridinium monothiophosphate in $3 \mathrm{ml}$ of water was passed through a column (1.4 by $40 \mathrm{~cm}$ ) of cation exchange resin, Amberlite IR-100-H, analytical grade, and a sufficient volume of distilled water was added to elute the free acid. The acidic portion of the effluent was collected in a flask, surrounded by an ice bath, and the cooled filtrate was lyophilized. A theoretical yield of thick, sirupy acid was obtained. 
Although the acid was hygroscopic and had an odor resembling hydrogen sulfide, it was quite stable at $-20^{\circ} \mathrm{C}$, as indicated by the analysis corresponding to monothiophosphoric acid monohydrate.

Analysis: Calculated for $\mathrm{H}_{3} \mathrm{PSO}_{3} \cdot \mathrm{H}_{2} \mathrm{O}: \mathrm{S}, 24.27$; P, 23.46; N. E., 132. Found: S, 24.26; P, 22.93; N. E., $130,129$.

Monothiophosphoric acid monohydrate gave a sulfur analysis of 24.26 percent after standing at $-20^{\circ} \mathrm{C}$ for 1 week and 24.23 percent after 2 weeks. However, when a sample was allowed to stand at $30^{\circ}$ in a glass-stoppered vial, in a desiccator, the sulfur value decreased to 11.54 percent after 1 week, and the phosphorus value increased to 25.54 percent. These analyses, in addition to the pronounced odor of hydrogen sulfide, indicated that the acid was decomposing to phosphoric acid monohydrate and hydrogen sulfide, as reported in the early literature [6].

\section{References}

[1] P. S. Pischumuka, J. Russ. Phys. Chem. Soc. 44, 1406 (1912); 56, 11 (1925).

[2] I. Cambi, Chimica e industria (Italy) 26, 97 (1944).

[3] L. Malatesta and R. Pizzotti, Chimica e industria (Milan) 27, 6 (1945).

[4] G. M. Kosalapoff, Organophosphorus compounds, p. 236, 256 (John Wiley \& Sons, Inc., New York, N. Y. 1950).

[5] E. Klingsberg and D. Papa, J. Am. Chem. Soc. 73, 4988 (1951).

[6] C. A. Wurtz, Ann. chim. phys. 20, 473 (1847); Compt. rend. 24, 288 (1847).

Washington, January 2, 1952. 